\title{
Percepção dos alunos de Ciências Contábeis sobre as atividades desenvolvidas pelo Programa de Educação Tutorial em Administração, Direito e Economia
}

\section{Students' Perception of Accounting about the activities developed by Tutorial Education Program in Management, Law and Economy}

\section{Geordana Mendonça Curcino}

Graduanda em Ciências Contábeis na Universidade Federal de Uberlândia

Endereço: Rua Newton Atheniel, nº 81, Bairro Jardim Milenium

CEP: 38447-368 - Araguari/MG - Brasil

E-mail: geordana.mc@ @otmail.com

Telefone: (34) 8865-7672

\section{Sirlei Lemes}

Doutora em Controladoria Contabilidade na Universidade de São Paulo

Professora da Faculdade de Ciências Contábeis e do Mestrado em Administração da

Universidade Federal de Uberlândia

Endereço: Av João Naves de Avila, 2121 - Campus Santa Mônica

Faculdade de Ciências Contábeis - Universidade Federal de Uberlândia

CEP: 38.400-902 - Uberlândia/MG - Brasil

E-mail: sirlemes@uol.com.br

Artigo recebido em 21/11/2011. Revisado por pares em 19/03/2012. Reformulado em 18/04/2012. Recomendado para publicação em 03/05/2012 por Sandra Rolim Ensslin (Editora Científica). Publicado em 28/06/2012. 


\title{
Resumo:
}

Este trabalho buscou identificar a percepção dos alunos de Ciências Contábeis em relação às atividades desenvolvidas pelo PET de áreas afins. Foi aplicado um questionário aos tutores e petianos de Administração, Direito e Economia, identificando-se as atividades que estes percebiam como mais relevantes. Verificou-se a percepção dos alunos de Ciências Contábeis em relação às atividades identificadas anteriormente. Além da maioria das atividades ter recebido boa avaliação, as atividades mais relevantes apontadas foram: seminários e palestras de profissionais (Ensino); eventos acadêmico-científicos (Pesquisa); e Semana do Contador (Extensão). Caracterizaram-se, assim, atividades extracurriculares relevantes que podem ser desenvolvidas nos cursos de Ciências Contábeis.

Palavras-chave: PET. Ciências contábeis. Ensino. Pesquisa. Extensão.

\begin{abstract}
:
This study searched to identify the students' perception of Accounting in relation to the activities developed by PET of similar areas. The activities which were perceived as being the most relevant were identified by a questionnaire applied to tutors and PET students. The perception of Accounting students was examined in relation to the activities identified previously. Despite most of the activities have received good evaluation, the most relevant emphasized by them were: seminars and speeches given by professionals (Teaching); academic-scientific events (Research); and accountant event (Extension). Relevant options of extracurricular activities were characterized to be developed in the Accounting courses.
\end{abstract}

Keywords: PET. Accounting. Teaching. Research. Extension.

\section{Introdução}

De acordo com o sítio do Ministério da Educação - MEC (2010a), o Programa de Educação Tutorial (PET) é um programa criado pelo governo federal brasileiro para apoiar atividades acadêmicas que integram ensino, pesquisa e extensão. O programa é formado por grupos tutoriais de aprendizagem, sob a orientação de um professor tutor, que realizam atividades extracurriculares que complementam a formação acadêmica do estudante e atendem às necessidades do próprio curso de graduação. O PET contempla atividades em diversas áreas do conhecimento, possuindo, no ano de 2010, 428 grupos instituídos pelo MEC.

A pesquisa foi desencadeada em função da necessidade do desenvolvimento de atividades extracurriculares e interdisciplinares na graduação em Ciências Contábeis, uma vez que se estima haver uma grande carência de atividades extracurriculares no citado curso em todo o País. De acordo com o portal do MEC (2010b), não existe, atualmente, nenhum grupo PET em Ciências Contábeis em andamento, o que pode comprometer a integração dos graduandos dessa área com a vivência acadêmica. Assim, a relevância do artigo fundamenta- 
se na necessidade da aplicação da tríade ensino-pesquisa-extensão no processo de formação dos discentes em Ciências Contábeis.

Nesse sentido, este trabalho consiste em um estudo sobre a percepção dos alunos de Ciências Contábeis, de uma instituição de ensino federal, em relação às ações dos grupos PET em áreas afins à Contabilidade, sendo elas a Administração, o Direito e a Economia. Ao identificar as atividades que os alunos perceberam como mais relevantes e necessárias à sua formação, esta pesquisa pode contribuir na orientação ao delineamento de propostas, tanto para programas como o PET, quanto para outros projetos acadêmicos voltados às especificidades dos cursos de Ciências Contábeis.

O propósito desta pesquisa consistiu em responder a seguinte questão: Qual é a percepção dos graduandos em Ciências Contábeis em relação às atividades desenvolvidas pelo PET de áreas afins?

Foram escolhidos para o cumprimento do propósito desta pesquisa os cursos de Administração, Direito e Economia, que, além de estarem alocados na mesma Área de Conhecimento do curso de Ciências Contábeis (Ciências Sociais Aplicadas), também têm uma proximidade histórica e de conhecimento, com inserção de várias disciplinas daqueles cursos no currículo de Ciências Contábeis. A fundamentação dessa escolha se baseia na hipótese de que as atividades realizadas pelo PET desses cursos são aplicáveis também aos cursos de Ciências Contábeis.

O objetivo geral deste estudo consistiu em identificar a percepção dos alunos de Ciências Contábeis em relação às atividades desenvolvidas pelo PET de áreas afins. Os objetivos específicos, por sua vez, consistiram em: listar as principais atividades realizadas pelos grupos PET dos cursos de Administração, Direito e Economia; identificar as vantagens proporcionadas pelas atividades do PET nesses cursos, na percepção de tutores e estudantes de Administração, Direito e Economia; e apontar, na percepção dos alunos de Ciências Contábeis, propostas de atividades extracurriculares a serem realizadas por meio do PET.

Este artigo está estruturado em cinco seções, incluindo esta inicial que descreve os aspectos introdutórios do estudo. A segunda seção apresenta as características e objetivos do PET, conceitua a tríade ensino, pesquisa e extensão no contexto do ensino superior no Brasil, assim como expõe as necessidades do curso de Ciências Contábeis quanto a atividades extracurriculares. Os aspectos metodológicos do trabalho são apresentados na terceira seção. A próxima seção traz sistematicamente as atividades desenvolvidas pelos grupos PET analisados, as vantagens proporcionadas pelas atividades do PET e, por fim, a percepção dos alunos de Ciências Contábeis em relação a tais atividades. Por último, a quinta seção apresenta as considerações finais da pesquisa.

\section{Referencial Teórico}

\subsection{Definição e características do PET}

Segundo Breuning et al. (2009, p. 481), o PET (Programa de Educação Tutorial) é um programa de excelência acadêmica cuja intencionalidade de criação foi a busca por melhorias no Ensino Superior brasileiro. O Ministério da Educação (2006, p. 4), por meio do Manual de Orientações Básicas do PET, esclarece que o Programa foi criado em 1979 pela Coordenação de Aperfeiçoamento de Pessoal de Nível Superior (CAPES) com o nome de Programa 
Especial de Treinamento. De acordo com Martins (2007a, p. 1), esse período foi importante para revelar a qualidade acadêmica do Programa e demonstrar a unidade dos seus integrantes na mobilização nacional para evitar a sua enunciada extinção.

Em 1999, a responsabilidade da gestão do Programa foi transferida para a Secretaria de Educação Superior do MEC (Sesu), e, em 2004, passou a ser chamado de Programa de Educação Tutorial. Atualmente, o PET é regulamentado pela Lei n. 11.180/2005 e pelas Portarias n. 3.385/2005, n. $1.632 / 2006$, n. $1.046 / 2007$, n. 591/2009 e n. 976/2010. A regulamentação do PET define as diretrizes para o funcionamento do Programa, a constituição administrativa e acadêmica, além de estabelecer as normas e a periodicidade do processo de avaliação nacional dos grupos (MEC, 2010a).

Dados do MEC (2006, p. 4) revelam que o Programa é composto por grupos tutoriais de aprendizagem e busca propiciar aos alunos condições para a realização de atividades extracurriculares que complementam a sua formação acadêmica. Dessa forma, o PET procura atender mais plenamente às necessidades do próprio curso de graduação e busca ampliar e aprofundar os objetivos e conteúdos programáticos que integram a grade curricular do curso (MEC, 2006, p. 4). Espera-se, então, que os cursos de graduação usuários do PET obtenham melhorias no tocante à qualidade acadêmica.

Martins (2007a, p. 3) define a Educação Tutorial como uma metodologia de ensino com compromissos epistemológicos, pedagógicos, éticos e sociais, que se efetiva por meio de grupos de aprendizagem, constituídos por estudantes, sob a orientação de professores tutores. Dentre as funções dos tutores, destacam-se as tarefas de estimular o interesse acadêmico do aluno e identificar suas potencialidades e qualidades a fim de promover a autonomia discente para analisar problemas, racionalizar criticamente e agir de forma ética e cidadã (MARTINS, 2007a, p. 3).

De acordo com o MEC (2006, p. 4), as atividades extracurriculares executadas no Programa têm como objetivo garantir aos alunos dos diversos cursos oportunidades de vivenciar experiências não presentes em estruturas curriculares convencionais. Nessas circunstâncias, o PET visa à formação global dos discentes e favorece a formação acadêmica, tanto para a integração no mercado profissional quanto para o desenvolvimento de estudos em programas de pós-graduação (MEC, 2006, p. 4). Assim, o PET oferece oportunidades de crescimento e desenvolvimento para o graduando.

O PET consiste em uma plataforma de alicerce para melhorias na educação, sendo ele um exemplo de Programa único na graduação, com o diferencial fundamental de indissociabilidade entre Ensino, Pesquisa e Extensão (BREUNING et al., 2009, p. 481). Nessa perspectiva, o objetivo geral do PET é promover a formação ampla e a qualidade acadêmica dos alunos de graduação envolvidos com o Programa, estimulando a fixação de valores que reforcem a cidadania e a consciência social de todos os participantes e a melhoria dos cursos de graduação (MEC, 2006, p. 7).

Segundo Xavier e Goulart (2007, p. 2), o fortalecimento do PET é essencial para a melhoria do ensino superior no Brasil. Os autores ainda afirmam que as bases do PET devem ser solidificadas nas instituições e cursos onde ele já atua, incentivando sua expansão entre universidades e cursos de graduação de todo o País.

O PET estimula o desenvolvimento da interdisciplinaridade, que consiste na "interação entre duas ou mais disciplinas; em que cada disciplina em contato é modificada e passa a depender, claramente, das outras. O enriquecimento é recíproco e acontece uma 
transformação de suas metodologias de pesquisa e de seus conceitos" (KLEIN, 1990 apud LEAL; OLIVEIRA; MIRANDA, 2010, p. 3). De acordo com Vieira (2008, p. 40), as vantagens da interdisciplinaridade são conhecimento de outras perspectivas; habilidade para sintetizar ou integrar assuntos ligados à área afim; ampliação de perspectivas e horizontes; aumento do pensamento criativo, original e não convencional; e aumento da habilidade de escutar pontos de vistas diferentes.

Com base nessas informações, é perceptível a importância do PET como fator construtivo para a formação acadêmica do discente, pois minimiza as barreiras de acesso ao conhecimento e estimula o estudante a um raciocínio mais abrangente das disciplinas, disseminando, assim, uma maior integração entre docentes e discentes.

\subsection{Objetivos fundamentais do ensino superior no Brasil}

Brown e Atkins (1988 apud PELEIAS et al., 2006, p. 133) destacam que, para a promoção do aprendizado efetivo, é necessário que as Instituições de Ensino Superior, juntamente com seus professores, melhorem suas estratégias de ensino e, ao mesmo tempo, ajudem seus alunos a melhorarem sua aprendizagem. Assim, ensino e aprendizagem caminham juntos para o aperfeiçoamento dos alunos: o ensino oferece um conjunto de ações para promover a aprendizagem, que é o processo de desenvolvimento do conhecimento. Martins et al. (2003 apud NOGUEIRA; ESPEJO, 2010, p. 3) ressaltam ainda que a aprendizagem acontece quando uma pessoa adquire um conhecimento que antes não detinha, podendo ser definida como a maneira como o indivíduo adquire, armazena e usa o conhecimento.

As atividades desenvolvidas no PET podem ser atribuídas como um exemplo de harmonização entre ensino e aprendizagem, pois, por meio de tais atividades, os discentes adquirem uma formação profissional e cidadã. Isso se torna um fator importante à medida que "a boa formação acadêmica e a educação continuada, cada vez mais, tornam-se elementos distintivos para o sucesso profissional” (PELEIAS et al., 2006, p. 38).

Nessas circunstâncias, Andere e Araujo (2008, p. 93) enfatizam que a finalidade do ensino superior vai além da formação do cidadão; cabe a ele a transmissão de cultura, a disseminação do conhecimento, a investigação científica, a formação de pesquisadores, o ensino de profissões e a prestação de serviços à comunidade. Assim, é necessário que o graduando receba uma formação global que lhe dê habilidades para tomar decisões e resolver conflitos no futuro profissional.

A Lei n. 9.394 (BRASIL, 1996), que estabelece as diretrizes e bases da educação nacional, expõe, no capítulo IV, os parâmetros da educação superior no Brasil. De acordo com o art. 43 deste capítulo, a educação superior tem como principais finalidades:

\footnotetext{
- estimular a criação cultural e o desenvolvimento do espírito científico e do pensamento reflexivo;

- formar diplomados nas diferentes áreas de conhecimento, aptos para a inserção em setores profissionais e para a participação no desenvolvimento da sociedade brasileira, e colaborar na sua formação contínua;

- incentivar o trabalho de pesquisa e investigação científica, visando o desenvolvimento da ciência e da tecnologia, e a criação e difusão da cultura;

- promover a divulgação de conhecimentos culturais, científicos e técnicos; e comunicar o saber através do ensino, de publicações ou outras formas;
} 


\begin{abstract}
- prestar serviços especializados à comunidade e estabelecer com esta uma relação de reciprocidade;

- promover a extensão, aberta à participação da população, visando à difusão das conquistas e benefícios resultantes da criação cultural e da pesquisa científica e tecnológica geradas na instituição.
\end{abstract}

O PET pode possibilitar a execução das finalidades acima apresentadas, uma vez que as atividades desenvolvidas pelo Programa proporcionam aos alunos oportunidades de aprofundarem em um universo acadêmico mais amplo. Dessa forma, o PET auxilia no cumprimento dos objetivos inerentes à Educação Superior no Brasil, possuindo grande representatividade no que tange à maior qualidade do ensino.

\title{
2.3. Ensino, pesquisa e extensão
}

O PET enfatiza o desenvolvimento da tríade ensino, pesquisa e extensão, fator que o distingue de outros programas oferecidos aos universitários no âmbito acadêmico. Assim, o Programa formula novas estratégias de aprendizagem a partir do delineamento de atividades extracurriculares, com vistas à melhor relação dos graduandos com os docentes e com a vida acadêmica.

O ensino consiste no ato de transmitir informações, de organizar as condições de aprendizagem para que o conhecimento seja construído. Representa uma face do processo educacional. (PELEIAS et al., 2006, p. 1). Martins (2007a, p. 5) acrescenta que

o ensino deve ter como horizonte a aprendizagem, processos interdependentes que dão corpo a uma relação em que a participação ativa do aluno, como agente de um ato criativo e realizador é imprescindível e onde se constroem novas capacidades, com transformações mútuas entre alunos e professores, haja vista as experiências diferenciadas desses atores.

Em relação à pesquisa, Bernardo, Nascimento e Nazareth (2010, p. 120) destacam que essa prática é uma importante forma de vivenciar a edificação do conhecimento, para o qual se faz necessário apropriar-se do conhecimento já existente, evitando a defasagem no ensino. Ferreira (2011, p.105) sustenta que o processo de pesquisa envolve a exploração da estrutura dos objetos mediante instrumentos epistemológicos e de métodos e técnicas adequados aos objetos pesquisados. Dessa forma, pesquisar é "dar ao objeto um contexto, num esforço de pensar a realidade, decifrando e descrevendo a partir de observações e investigações que conduzam à busca de respostas" (FERREIRA, 2011, p. 105).

A extensão, por sua vez, consiste em um processo educativo, cultural e científico, que articula o ensino e a pesquisa de forma indissociável e viabiliza a relação transformadora entre universidade e sociedade (SILVA, QUIMELLI, 2006, p. 282). De acordo com Ferreira (2011, p. 104), a extensão é um dos princípios que constituem a base da universidade, uma vez que entender a concepção de extensão universitária é o primeiro passo na construção e adoção de políticas na área e na normalização das ações.

Martins (2007b, p. 5) afirma que a pesquisa e a extensão terão a máxima expressão na formação superior, quando unidas ao ensino. Martins (2007b, p. 5) acrescenta que, "se por um lado o ensino coloca o aluno em relação com o produto da ciência, a pesquisa o coloca em relação com o seu desenvolvimento, instrumentalizando-o para produzir conhecimentos a 
partir de sua futura atuação profissional". Nesse contexto, "o PET pode contribuir para avançar o debate sobre a temática da indissociabilidade entre ensino, pesquisa e extensão, no âmbito da graduação e da pós-graduação, consolidando-a como campo de investigação, respeitadas as singularidades próprias de cada contexto" (MARTINS, 2007a, p. 6).

Para reforçar a ideia de interação entre a tríade proposta pelo PET, Xavier e Goulart (2007, p. 1) destacam que ensino, pesquisa e extensão são "pilares básicos que sustentam o saber universitário". Ainda segundo esses autores (2007, p. 1), enfatizar ensino, pesquisa e extensão, o aspecto político adquirido ao longo dos anos pelo Programa e a ideia de tutoria de pequenos grupos por docentes capacitados para a função definem os ingredientes básicos necessários para a formação de líderes. Nesse contexto, a interação entre ensino, pesquisa e extensão é essencial para a promoção do desenvolvimento e modernização do ensino superior no País.

\subsection{O curso de Ciências Contábeis}

Sontag et al. (2007, p. 2) afirmam que o bacharel em Ciências Contábeis é o profissional que identifica e apresenta soluções para os diversos problemas contábeis e gerenciais pertinentes às entidades, consciente da busca permanente de atualização e aperfeiçoamento profissional e pessoal. Assim, o profissional em Ciências Contábeis deve conhecer as práticas contábeis, societárias, fiscais e tributárias aplicadas às entidades, tendo compromisso com a sociedade, visando aplicar seus conhecimentos em prol do engrandecimento da mesma (SONTAG et al., 2007, p. 2).

Costa (p. 163, 2003 apud PELEIAS et al., p. 247, 2006) destaca que a formação do futuro contador deve ter como resultado um profissional direcionado e capacitado, tanto para a mensuração de números e valores como para a cultura geral e humanística. Dessa maneira, o profissional deve se posicionar em um ambiente econômico, social e institucional, interagindo com pessoas e grupos distintos.

Marion (2001 apud Castro, 2009, p. 11) defende que "a educação para os futuros contadores deveria produzir profissionais que tivessem amplo conjunto de habilidades e conhecimentos". Assim, o processo de ensino e aprendizagem na formação do profissional contábil deve englobar a criatividade, inovação, competência, e a capacidade de se adequar à era da globalização, para que este possa, enfim, enfrentar o novo mercado de trabalho.

Peleias et al. (2006, p. 184) destacam as competências e habilidades necessárias aos profissionais de Contabilidade que devem ser oferecidas pelos cursos de graduação em Ciências Contábeis: usar a linguagem e a terminologia contábil, ter visão sistêmica e interdisciplinar, domínio da legislação, capacidade de gerenciar e trabalhar em grupos, domínio da expertise contábil, da tecnologia da informação, da ética e da proficiência.

$\mathrm{O}$ art. $3^{\circ}$ da CNE/CES, n. 10 (BRASIL, 2004), determina que o curso de graduação em Ciências Contábeis deve ensejar condições para que o futuro contabilista esteja capacitado para:

I - compreender as questões científicas, técnicas, sociais, econômicas e financeiras, em âmbito nacional e internacional e nos diferentes modelos de organização;

II - apresentar pleno domínio das responsabilidades funcionais envolvendo apurações, auditorias, perícias, arbitragens, noções de atividades atuariais e de quantificações de informações financeiras, patrimoniais e governamentais, com a plena utilização de inovações tecnológicas; 
III - revelar capacidade crítico-analítica de avaliação, quanto às implicações organizacionais com o advento da tecnologia da informação.

A partir das habilidades e competências ressaltadas anteriormente, percebe-se o caráter multifuncional exigido dos contabilistas. Ao mesmo tempo em que necessita compreender o funcionamento das instituições empresariais, o contabilista precisa, também, entender as transformações do mundo ao seu redor.

Por outro lado, a área contábil ainda apresenta uma carência expressiva quanto a pesquisadores, apesar da prática constante de seus conhecimentos teóricos no ramo operacional e financeiro (MARION, 2003 apud Castro, 2009, p. 7). Assim, Castro (2009, p. 7) destaca que essa carência de pesquisadores reflete diretamente na qualidade do ensino oferecido aos futuros contadores e no resultado esperado pelo mercado de trabalho.

Segundo Antunes et al. (2005, p. 65), "[n]os cursos de graduação em Ciências Contábeis ainda se verifica uma grande quantidade de instituições que priorizam a função técnica do contador esquecendo-se que os sistemas de informações disponíveis realizam muito bem essa função". Em contrapartida, o contador necessita de uma formação abrangente que lhe permita atuar diretamente na tomada de decisões das empresas. Leal e Cornachione (2006, p. 96) acrescentam que no contexto atual o contador não pode mais se limitar às habilidades as quais utiliza exclusivamente em suas atividades rotineiras. Assim, os autores apontam que os contadores devem ter uma visão ampliada que considere o ambiente organizacional e que possa ser crítica na medida em que assuma atitudes, defenda valores, se engaje em campanhas, se sacrifique mesmo, porém de forma consciente, autônoma e responsável (NÉRICI, 1989, p. 30 apud LEAL; CORNACHIONE, 2006, p. 96).

Segundo Leal, Oliveira e Miranda (2010, p. 2), "no ensino de contabilidade, o isolamento das disciplinas cria obstáculos para se estabelecer as interrelações necessárias para superação da extrema racionalidade técnica que permeia a construção do conhecimento na área". Nessas perspectivas, a interdisciplinaridade oferecida pelo PET, por meio do desenvolvimento de atividades de ensino, pesquisa e extensão, se torna cada vez mais necessária na formação dos contadores. O PET proporcionaria aos estudantes do curso de Ciências Contábeis um diferencial curricular e uma maior interação com a comunidade universitária, assim como já o fazem em outros cursos.

Ressalta-se, assim, a relevância de programas como o PET para os cursos de Ciências Contábeis, que, considerados em seu conjunto no Brasil, ainda carecem de práticas que proporcionem aos graduandos uma visão crítico-analítica das disciplinas que integram a ementa do curso uma maior interação com os docentes e o aprimoramento da capacidade de trabalhar em grupos. Especificamente quanto à formação técnica dos discentes do curso, a implementação de PET em cursos de Ciências Contábeis poderá resultar em maior embasamento prático e, consequentemente, maior aprimoramento, a partir de atividades acadêmicas realizadas pelo Programa.

Observa-se assim que um PET para os cursos de Ciências Contábeis pode permitir uma visão mais ampla da formação contábil, principalmente diante das recentes mudanças pelas quais passa a contabilidade brasileira que, em 2010, migrou em sua quase totalidade das regras contábeis locais para as internacionais. Essa migração, combinada com benefícios em termos de integração com uma contabilidade globalizada, maior transparência dos relatórios contábeis e ganhos na acirrada disputa por investidores externos, trouxe à tona deficiências na formação do profissional contábil. Esse profissional, ainda sendo remodelado pelos diversos

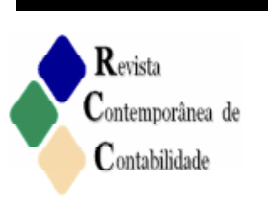


cursos por todo o País, sai de uma posição aparentemente confortável no processo de relatar o ocorrido com as empresas para uma situação bem mais atuante como decisor entre diversas opções no registro do fato contábil ocorrido.

\section{Aspectos Metodológicos}

\subsection{Delineamento da pesquisa}

Nesta seção são descritos os procedimentos metodológicos adotados para a realização deste estudo. Quanto aos objetivos, este trabalho classifica-se como descritivo, uma vez que mediu a percepção dos discentes em relação a determinadas variáveis. Assim, de acordo com Gil (2002, p. 42), esse tipo de pesquisa tem com objetivo principal a descrição das características de determinada população ou fenômeno, assim como o estabelecimento de relações entre as variáveis.

Quanto aos procedimentos técnicos utilizados, pode-se classificar esta pesquisa como um levantamento, com a utilização de questionários e pesquisa documental como instrumentos de coleta de dados. Conforme Gil (2002, p. 50), o levantamento caracteriza-se "pela interrogação direta das pessoas cujo comportamento se deseja conhecer". Assim, os dados coletados foram tratados de forma quantitativa, e os questionários foram utilizados durante as duas etapas da pesquisa, as quais são caracterizadas nas seções 3.2 e 3.3 a seguir.

\subsection{Primeira etapa}

$\mathrm{Na}$ primeira etapa do estudo, foram identificadas as atividades desenvolvidas pelos grupos PET dos cursos de Administração, Direito e Economia, certificados no ano de 2010. Primeiramente, os websites dos grupos PET selecionados foram acessados para leitura dos Relatórios de Atividades, disponibilizados pelos grupos. A seguir, foram identificadas as atividades consideradas mais relevantes por meio da aplicação de questionários aos tutores e alunos dos grupos PET. Adicionalmente, recorreu-se ao Currículo Lattes dos tutores do PET, disponíveis na base de dados do Conselho Nacional de Desenvolvimento Científico e Tecnológico $(\mathrm{CNPq})$, para identificar os e-mails de contato.

Assim, os questionários foram enviados por correio eletrônico aos professores tutores e alunos do PET durante o período de janeiro a abril de 2011. O e-mail continha uma carta de apresentação e o endereço do site com o questionário. Após o envio, foram realizadas ligações telefônicas enfatizando a importância da participação na pesquisa por meio do preenchimento do questionário.

A população envolveu todos os integrantes dos grupos PET analisados, totalizando 28 professores tutores e 336 alunos do PET. Conforme dados do MEC, em 2010, existiam no Brasil 28 grupos PET em Administração, Direito e Economia, conforme apresentado no Quadro 1.

O questionário foi composto por três blocos, sendo o primeiro destinado a identificar a função do respondente no PET (tutor ou aluno), a instituição à qual pertence o respondente e o curso de graduação em que atua. $\mathrm{O}$ segundo bloco consistiu em uma pergunta aberta que objetivou identificar as principais atividades realizadas pelo PET nos cursos que compuseram 
a amostra, consideradas relevantes para formação profissional/pessoal, de acordo com a percepção dos respondentes. O terceiro bloco do questionário, por sua vez, consistiu em identificar as possíveis vantagens agregadas à execução do Programa. Para isso, foi formulada uma série de afirmativas de acordo com as características essenciais do Programa, embasadas no Manual de Orientações Básicas do PET.

Quadro 1 - Grupos PET de 2010 por subárea de conhecimento

\begin{tabular}{|c|c|c|c|}
\hline Administraçã & \multicolumn{2}{|c|}{ Economia } & Direito \\
\hline UFAM & UNIR & UFPR & UFMA \\
\hline UFLA & UFT & UNIJUI & UFPR \\
\hline UFMG & UFAL & UFES & UFSC \\
\hline UFV & UEFS & UFMG & PUC/RJ \\
\hline UNESP & UFC & UFU & USP \\
\hline \multirow[t]{3}{*}{ USP } & UFCG & UFF & UNB \\
\hline & UFPE & PUC/RJ & \\
\hline & UEM & UNB & \\
\hline Total: 6 & \multicolumn{2}{|c|}{ Total: 16} & Total: 6 \\
\hline
\end{tabular}

Fonte: Dados do Ministério da Educação (2010b).

Assim, essas questões foram estruturadas de forma que os respondentes assinalassem sua avaliação em relação às contribuições que as atividades do PET proporcionam para o cumprimento das vantagens propostas, com uma escala de cinco níveis, de Péssimo a Ótimo. Nessa perspectiva, buscou-se identificar os aspectos positivos da execução de tal programa.

\subsection{Segunda etapa}

Na segunda etapa do estudo, foi realizado um levantamento, com a aplicação de um questionário aos alunos do curso de Ciências Contábeis de uma universidade federal, localizada em Minas Gerais, durante o mês de maio de 2011. O questionário foi aplicado a dez turmas, pertencentes aos turnos Integral e Noturno. A população total estimada das turmas, com base na quantidade de alunos matriculados, era de 427 alunos. Porém, obteve-se uma amostra de 298 questionários respondidos, devido à evasão de alguns alunos matriculados, da ausência em sala no dia da aplicação do questionário, e ao fato de 13 questionários serem entregues em branco. As turmas escolhidas para aplicação do questionário incluem alunos que se encontravam no início ( $1^{\circ}$ e $2^{\circ}$ períodos $)$, meio $\left(4^{\circ}, 5^{\circ}\right.$ e $6^{\circ}$ períodos), e fim do curso ( $9^{\circ}$ e $10^{\circ}$ períodos), assegurando uma diversidade significativa na amostra, de forma a permitir capturar as impressões de alunos ingressantes, de meio de curso e daqueles já quase se graduando.

De acordo com os resultados detectados na primeira etapa da pesquisa, foram identificadas as vinte atividades mais citadas entre tutores e alunos de grupos PET. Dessa forma, o questionário aplicado nessa etapa da pesquisa foi elaborado com vinte tópicos relacionados às principais atividades desenvolvidas pelos grupos PET analisados, identificadas no âmbito de ensino, pesquisa e extensão. Os alunos assinalaram sua opinião em 
relação ao desenvolvimento de tais atividades no curso de Ciências Contábeis, de acordo com a escala Likert, apresentada com as opções: Discordo totalmente, Discordo em parte, Nem concordo nem discordo, Concordo em parte, Concordo totalmente.

Todos os tópicos elaborados foram pré-testados com 12 alunos de diversos períodos. A partir da tabulação dos dados, os escores atribuídos por todos os respondentes foram analisados por meio de estatística descritiva, com a indicação das médias e desvios-padrão.

\section{Análise dos Resultados}

\subsection{Atividades desenvolvidas pelo PET}

Com o primeiro bloco do questionário, foram identificadas ao todo 92 respostas ao questionário, sendo 18 tutores e 74 alunos do grupo PET. Em termos de áreas dos respondentes, 19 são do curso de Administração, 20 de Direito e 53 de Economia. Isso permitiu contemplar as três áreas componentes da amostra.

Pela observação das atividades relatadas nas páginas eletrônicas dos grupos PET analisados e da aplicação de questionários aos professores tutores e alunos, pode-se destacar, conforme os Quadros 2, 3 e 4 a seguir, as principais atividades realizadas por grupos PET dos cursos de Administração, Direito e Economia. As atividades estão dispostas conforme a tríade (ensino, pesquisa e extensão) estabelecida pelos objetivos propostos pelo MEC em relação ao PET. Os respondentes foram interrogados com a seguinte questão no segundo bloco do questionário: "Das atividades desenvolvidas no Programa de Educação Tutorial, quais você considera como mais relevantes para sua formação profissional/pessoal?". Os números entre parênteses indicam a reincidência das atividades em mais de um grupo analisado.

No Quadro 2, estão descritas as principais atividades realizadas pelos grupos PET dos cursos de Administração.

\section{Quadro 2 - Principais atividades desenvolvidas pelo PET em Administração}




\begin{tabular}{|c|l|}
\hline Tríade & \multicolumn{1}{|c|}{ ATIVIDADES } \\
\hline Ensino & $\begin{array}{l}\text { Seminários apresentados e assistidos (3); Sessão de filmes (3); Participação e realização de } \\
\text { Minicursos (3); Grupo de estudos dirigidos (2); Palestras (2); Leitura e debate de textos (2); } \\
\text { Minicurso de Excel (2); PET-English (1); Promoção de oficinas para alunos de graduação (1); } \\
\text { Grupos de Debate Interdisciplinar (1); Monitoria (1); Recepção aos calouros (1); Curso de } \\
\text { comunicação (1); Defesas de mestrado e doutorado assistidas (1). }\end{array}$ \\
\hline Pesquisa a & $\begin{array}{l}\text { Pesquisa coletiva focada em um tema definido pelo tutor (4); Participação em eventos } \\
\text { acadêmico-científicos (3); Organização de eventos acadêmico-científicos (2); Realização } \\
\text { individual de projetos de pesquisa orientados pelo tutor (2); Seminários das pesquisas } \\
\text { realizadas (1); Apresentação de pesquisas em congressos (1); Elaboração de monografia (1); } \\
\text { Publicações de artigos (1). }\end{array}$ \\
\hline Extensão & $\begin{array}{l}\text { Oficina nas escolas (3); Programas desenvolvidos para crianças (2); Visitas técnicas (1); } \\
\text { Semana do Administrador (1); Integração universidade x ensino médio (1); Mostra } \\
\text { interinstitucional (1); Doação de alimentos (1); Apresentação do PET aos alunos ingressantes } \\
\text { (1); Participação nos órgãos colegiados (1); Desenvolvimento e gerenciamento de projetos } \\
\text { (1); Acessoria em empresas e cooperativas (1). }\end{array}$ \\
\hline
\end{tabular}

Fonte: Dados da pesquisa.

Destaca-se a 'pesquisa coletiva focada em um tema definido pelo tutor' como a atividade considerada mais relevante pelos respondentes.

No Quadro 3, estão descritas as principais atividades realizadas pelos grupos PET dos cursos de Direito.

Quadro 3 - Principais atividades desenvolvidas pelo PET em Direito

\begin{tabular}{|c|l|}
\hline Tríade & \multicolumn{1}{|c|}{ ATIVIDADES } \\
\hline Ensino & $\begin{array}{l}\text { Leitura e discussão de textos/ debates (2); Grupos de estudos (2); Palestras (2); Preparação } \\
\text { de material didático (2); Seminários (1); Fichamentos realizados através de leitura de textos } \\
\text { (1); PET-Literatura (1); PET-Cinema (1); Reformulação do Projeto Político-Pedagógico do } \\
\text { curso (1); Participação de aulas na graduação e pós-graduação, para conhecimento do } \\
\text { cotidiano da sala de aula (1); Estudos interdisciplinares (1). }\end{array}$ \\
\hline Pesquisa & $\begin{array}{l}\text { Grupos de pesquisa/ pesquisa coletiva (4); Elaboração de artigos para publicação em } \\
\text { periódicos científicos (3); Pesquisas individuais com temas de livre escolha (2); Seminário/ } \\
\text { palestra sobre as pesquisas realizadas (2); Pesquisa conjunta através de uma linha de pesquisa } \\
\text { atual (1); Projetos de Iniciação Científica (1). }\end{array}$ \\
\hline Extensão & $\begin{array}{l}\text { Universitários vão à escola (2); Jornada de Iniciação Científica (1); CICLO PET com a } \\
\text { apresentação das pesquisas individuais (1); Organização juntamente com professores de curso } \\
\text { de formação jurídica para lideranças comunitárias (1);Minicursos oferecidos à comunidade(1). }\end{array}$ \\
\hline
\end{tabular}

Fonte: Dados da pesquisa.

Grupos de pesquisa/ pesquisa coletiva' foi a atividade destacada pelos respondentes como a mais relevante para suas formações.

Por último, no Quadro 4, estão descritas as principais atividades realizadas pelos grupos PET dos cursos de Economia.

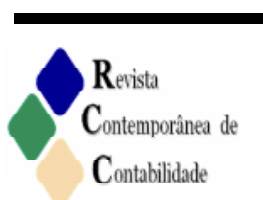


As 'oficinas de debates/ discussão de textos' e 'participação em eventos científicos nacionais com apresentação de trabalhos/ publicações' constituem as atividades que, na opinião dos respondentes, mais contribuíram com suas formações profissional e pessoal.

As atividades desenvolvidas no PET, consideradas como mais relevantes para a formação profissional/pessoal dos alunos de grupos PET e tutores, reforçam a ideia de Xavier e Goulart (2007, p. 1) de que o ensino, a pesquisa e a extensão são pilares básicos que sustentam o saber universitário. Conforme se observa nesses resultados, uma série de atividades ligadas a esta tríade foram consideradas relevantes, destacando a sua importância para a promoção do desenvolvimento e modernização do ensino superior no País.

Assim, com base nas atividades relatadas por grupos PET em áreas afins do curso de Ciências Contábeis, nota-se a viabilidade de realização dessas neste curso, devido à proximidade de conteúdo dos cursos e da flexibilidade das atividades. Verifica-se, assim, que todas as atividades expostas acima podem ser testadas e desenvolvidas em grupos PET específicos para o curso de Ciências Contábeis.

Quadro 4 - Principais atividades desenvolvidas pelo PET em Economia 


\begin{tabular}{|c|c|}
\hline Tríade & ATIVIDADES \\
\hline Ensino & $\begin{array}{l}\text { Oficina de debates/ discussão de textos (10); Seminários de profissionais de economia (9); } \\
\text { Monitoria voluntária (7); Oficina de leituras (7); Grupos de estudos (6); Palestras (6); } \\
\text { Minicursos sobre o mercado financeiro e política econômica (5); ; Sessão de vídeo (4); Estudo } \\
\text { de língua estrangeira/ inglês instrumental (4); Recepção de calouros (3); Encontros com a pós- } \\
\text { graduação (2); Orientação de temas para pesquisas e monografias (2); Sugestão de novas } \\
\text { metodologias de ensino (1); CINE-PET (1); Estudos interdisciplinares (1); Estudos } \\
\text { avançados (1); Minicursos de softwares econométricos (1); Minicurso de informática aos } \\
\text { petianos (1). }\end{array}$ \\
\hline Pesquisa & $\begin{array}{l}\text { Participação em eventos científicos nacionais com apresentação de trabalhos/ publicações } \\
\text { (10); Pesquisa individual acerca de um tema escolhido pelo aluno, sob orientação de um } \\
\text { professor (7); Pesquisas coletivas (6); Seminários e discussão sobre o andamento das } \\
\text { pesquisas (6); Elaboração de artigos (6); Organização de eventos acadêmico-científicos (3); } \\
\text { Projeto de análise da Conjutura Econômica brasileira e/ou mundial (2); Participação em } \\
\text { encontros internacionais (2); Realização de monografias anuais (1); Publicação das pesquisas } \\
\text { em formato de livro (1); Pesquisa de motivos de evasão no curso de Economia (1). }\end{array}$ \\
\hline Extensão & $\begin{array}{l}\text { Elaboração do periódico do PET/ colunas em jornais (5); Encontros entre os petianos/ } \\
\text { reuniões periódicas (5); Publicação de revista com assuntos econômicos (4); Blog/website da } \\
\text { economia (4); Projeto Economia nas escolas (3); Realização do Mural do PET (3); } \\
\text { Oferecimento de minicursos para transmissão de conhecimentos básicos de economia para a } \\
\text { população (3); Semana do economista (3); Intervivência universitária com outros grupos PET } \\
\text { (3); Jornada PET de Economia (2); Representação no InterPet (2); Organização de } \\
\text { movimentos sociais (2); Organização de eventos que priorizam a responsabilidade social/ } \\
\text { projetos sociais/ trabalho voluntário (2); Levantamento de cesta básica (2); Workshop (1); } \\
\text { Apresentação Teatral (1); Programa na rádio da universidade (1); Projeto Sustentabilidade } \\
\text { (1); Elaboração e Apresentação de resenhas sobre assuntos em pauta na mídia (1); Estágio } \\
\text { empresarial (1); Consultoria econômica (1); Palestras sobre finanças pessoais (1); Visita } \\
\text { técinica (1). }\end{array}$ \\
\hline
\end{tabular}

Fonte: Dados da pesquisa.

\subsection{Vantagens das atividades desenvolvidas pelo PET}

Por meio da aplicação do questionário aos professores tutores e alunos, buscou-se, além da identificação das atividades mais relevantes desenvolvidas pelos grupos PET, identificar as vantagens que o PET proporciona para os alunos e cursos de graduação que desenvolvem tal Programa.

No terceiro bloco do questionário, conforme já mencionado, foram formuladas afirmativas de acordo com as características essenciais do Programa, tratados no Manual de Orientações Básicas do PET. Assim, os respondentes foram interrogados da seguinte forma:

"Em relação ao Programa de Educação Tutorial desenvolvido em seu curso, qual sua avaliação sobre a contribuição das atividades do PET para a execução das vantagens elencadas abaixo?" Os resultados estão estruturados na Tabela 1 a seguir, considerando a mesma amostra de 92 respondentes.

O desenvolvimento de 'novas práticas e experiências pedagógicas no âmbito do curso de graduação', em sua generalidade, está sendo enquadrado dentro de um nível 'Bom' a 'Ótimo', ou seja, a maioria dos respondentes considera que as ações do PET fornecem 
elevada contribuição para a promoção dessa vantagem. Entretanto, $24 \%$ dos respondentes ainda consideram sua execução 'Regular' ou 'Fraca', concluindo-se que essa vantagem pode ser mais disseminada nos grupos PET para a promoção do desenvolvimento acadêmico.

Tabela 1 - Avaliação das vantagens do PET

\begin{tabular}{|c|c|c|c|c|c|}
\hline $\begin{array}{c}\text { Vantangens } \\
\text { do PET }\end{array}$ & \begin{tabular}{|c}
1 \\
Novas práticas e \\
expe riências \\
pedagógicas no \\
âmbito do curso
\end{tabular} & \begin{tabular}{|c|}
2 \\
Inovação e \\
desenvolvimento \\
do curso de \\
graduação;
\end{tabular} & \begin{tabular}{|c|}
3 \\
Crescimento \\
profissional \\
dos alunos \\
petianos;
\end{tabular} & $\begin{array}{c}4 \\
\text { Integração } \\
\text { entre ensino, } \\
\text { pesquisa e } \\
\text { extensão; }\end{array}$ & \begin{tabular}{|c|}
5 \\
Realização de \\
atividades com \\
caráter \\
inte rdis ciplinar;
\end{tabular} \\
\hline Avaliação & de graduação; & & & & \\
\hline Ótimo & $29,35 \%$ & $34,78 \%$ & $60,87 \%$ & $27,17 \%$ & $38,04 \%$ \\
\hline Bom & $46,74 \%$ & $45,65 \%$ & $33,70 \%$ & $58,70 \%$ & $43,48 \%$ \\
\hline Regular & $19,57 \%$ & $15,22 \%$ & $4,35 \%$ & $14,13 \%$ & $15,22 \%$ \\
\hline Fraco & $4,35 \%$ & $4,35 \%$ & $1,09 \%$ & $0 \%$ & $3,26 \%$ \\
\hline Péssimo & $0 \%$ & $0 \%$ & $0 \%$ & $0 \%$ & $0 \%$ \\
\hline Não se aplica & $0 \%$ & $0 \%$ & $0 \%$ & $0 \%$ & $0 \%$ \\
\hline
\end{tabular}

Fonte: Dados da pesquisa.

A segunda vantagem apontada, conforme também se observa na Tabela 1, consiste na 'inovação e desenvolvimento do curso de graduação'. Em relação a essa variável, observa-se que cerca de $80 \%$ dos respondentes consideram que esta vantagem está sendo efetivada pelo PET em um nível 'Bom' a 'Ótimo'. Isso demonstra que o PET é um importante fator inovador para os cursos de graduação de todo o País.

Pode-se notar, ainda na Tabela 1, que o 'crescimento profissional dos alunos petianos' foi o aspecto que recebeu o maior número de avaliações no conceito 'Ótimo', demonstrando que as ações do PET possuem elevada contribuição para a execução dessa vantagem. Esse fato pode ser explicado porque, no momento em que os alunos que desenvolvem o PET possuem contato com experiências acadêmicas e profissionais, são identificadas oportunidades de aprimoramento dos conhecimentos, a partir de atividades que buscam a integração entre ensino, pesquisa e extensão.

$\mathrm{Na}$ quarta vantagem apontada, buscou-se avaliar em que nível o PET contribui para a integração entre ensino, pesquisa e extensão. Em relação às respostas obtidas, pode-se notar que a maior parte da amostra $(58,70 \%)$ considera que o PET contribui para a integração entre ensino, pesquisa e extensão em um nível 'Bom'. Assim, pode-se estimar que os objetivos inerentes ao PET referentes à aplicação da tríade ensino, pesquisa e extensão estão sendo cumpridos com sucesso. Por outro lado, a não escolha dos conceitos 'Péssimo' e 'Fraco', em relação a esse tópico, demonstra o fortalecimento do PET e uma elevada integração universitária. Nessa perspectiva, por meio da integração dessa tríade, estima-se que o PET adquire vantagens em relação a outros programas que buscam atender a esses fatores de forma separada. Esse resultado evidencia a afirmação realizada por Breuning et al. (2009, p. 481) de que o PET é um exemplo de Programa único na graduação, com o diferencial fundamental de indissociabilidade entre ensino, pesquisa e extensão, sendo uma plataforma de alicerce para melhorias na educação. 
Mais de $80 \%$ (Tabela 1) dos respondentes julgaram que o PET contribui para a realização de atividades de caráter interdisciplinar em um nível 'Bom' a 'Ótimo'. Assim, percebe-se que está sendo cumprida a finalidade do PET, conforme o MEC (2006, p. 9), que estabelece que "o PET pretende atuar sobre a graduação a partir do desenvolvimento de ações coletivas, de caráter interdisciplinar, objetivando a formação de um cidadão com ampla visão do mundo e com responsabilidade social".

No geral, a identificação das influências dos programas PET nos cursos de Administração, Direito e Economia possibilitaram o conhecimento das vantagens que esse Programa pode propiciar em relação ao desenvolvimento acadêmico e profissional, ressaltando a sua importância, bem como a necessidade de sua expansão e aprimoramento.

\subsection{Percepção dos alunos de Ciências Contábeis em relação às atividades do PET}

Após o levantamento de dados junto aos alunos do curso de Ciências Contábeis, partiu-se para a tabulação das respostas e utilização da estatística descritiva para fundamentar a análise. Os alunos de Ciências Contábeis foram confrontados com a seguinte questão: "Das atividades listadas abaixo, assinale seu grau de concordância/discordância em relação ao desenvolvimento de tais atividades no curso de Ciências Contábeis, com base na relevância para sua formação acadêmica". A seguir, são apresentados os resultados referentes ao questionário aplicado aos alunos de Ciências Contábeis com as médias, de acordo com a escala tipo Likert, e desvios-padrão das respostas dos 298 respondentes. As atividades foram listadas por ordem decrescente das médias.

A Tabela 2 demonstra o posicionamento dos discentes em relação ao desenvolvimento de atividades voltadas para a área de ensino, percebendo-se que as médias de todas as atividades propostas variaram de 4 a 5 , ou seja, todos os respondentes concordam parcialmente ou totalmente com a realização de tais atividades no curso de Ciências Contábeis.

Tabela 2 - Percepção dos alunos de Ciências Contábeis em relação às atividades de ensino

\begin{tabular}{|l|c|c|}
\hline \multicolumn{1}{|c|}{ ATIVIDADES NA ÁREA DE ENSINO } & Média & Desvio Padrão \\
\hline 1. Seminários/ Palestras de profissionais de Contabilidade & 4,7081 & 0,6606 \\
\hline 2. Monitoria & 4,6250 & 0,7532 \\
\hline 3. Participação e realização de minicursos & 4,6172 & 0,7071 \\
\hline 4. Curso de língua estrangeira & 4,5952 & 0,8238 \\
\hline 5. Grupos de estudos formados por alunos & 4,2517 & 0,9299 \\
\hline 6. Oficina de debates/ leitura e discussão de textos & 4,2177 & 0,9421 \\
\hline 7.Sessão de vídeos/ filmes & 4,0174 & 1,0724 \\
\hline
\end{tabular}

Fonte: Dados da pesquisa.

A primeira atividade, que consiste na realização de 'seminários e palestras de profissionais de Contabilidade', é a atividade de ensino que os discentes concordam em maior grau com seu desenvolvimento. Por sua vez, a 'sessão de vídeos/filmes' é a atividade que foi atribuída a menor média, a qual se aproximou do número 4, demonstrando que os alunos concordam em parte com sua realização. Além disso, percebe-se que na área de ensino houve 
uma menor dispersão das médias em relação às demais atividades. Isso pode ser interpretado como maior uniformidade da opinião dos alunos em relação ao desenvolvimento das atividades enquadradas nessa área.

$\mathrm{O}$ interesse dos alunos pelas atividades de ensino se fundamenta na necessidade percebida de maiores conhecimentos, uma vez que, segundo Peleias et al. (2006, p. 1), o ensino é uma face do processo educacional que transmite informações e organiza as condições de aprendizagem para a construção do conhecimento.

$\mathrm{Na}$ Tabela 3, estão escalonadas as atividades da área de pesquisa de acordo com a percepção dos alunos quanto à sua relevância. Assim como ocorreu com as atividades de ensino, as médias de todas as atividades propostas deste bloco variaram de 4 a 5 , ou seja, todos os respondentes concordam parcialmente ou totalmente com a realização de tais atividades.

Tabela 3 - Percepção dos alunos de Ciências Contábeis em relação às atividades de pesquisa

\begin{tabular}{|l|c|c|}
\hline \multicolumn{1}{|c|}{ ATIVIDADES NA ÁREA DE PESQUISA } & Média & Desvio Padrão \\
\hline 1. Organização de eventos acadêmico-científicos & 4,4881 & 0,8486 \\
\hline $\begin{array}{l}\text { 2. Participação em eventos científicos com apresentação } \\
\text { de trabalhos/ publicações }\end{array}$ & 4,4524 & 0,8442 \\
\hline $\begin{array}{l}\text { 3. Seminários/ Palestras sobre as pesquisas de Iniciação } \\
\text { Científica da FACIC }\end{array}$ & 4,3636 & 0,9056 \\
\hline 4. Grupos de pesquisa/ pesquisa coletiva & 4,2881 & 2,5224 \\
\hline $\begin{array}{l}\text { 5. Pesquisa individual com temas de livre escolha, sob } \\
\text { orientação de um professor }\end{array}$ & 4,2290 & 0,9487 \\
\hline 6. Elaboração de artigos & 4,1678 & 1,0598 \\
\hline
\end{tabular}

Fonte: Dados da pesquisa.

A 'organização de eventos acadêmico-científicos' foi a atividade com maior grau de aceitação. Por outro lado, a 'elaboração de artigos' foi a atividade com menor média de concordância.

$\mathrm{O}$ anseio dos alunos pela realização de atividades de pesquisa se torna relevante na medida em que permite a apropriação do conhecimento já existente, obtido por meio das atividades de ensino. Conforme foi citado anteriormente, a execução dessas atividades é importante porque consiste em uma forma de vivenciar a edificação do conhecimento dos alunos (BERNARDO; NASCIMENTO; NAZARETH; 2010, p. 120).

A Tabela 4 lista as atividades de extensão com suas respectivas médias e desviospadrão, quanto à percepção dos alunos em relação ao desenvolvimento de tais atividades no curso de Ciências Contábeis.

Nota-se, pela Tabela 4, que as duas primeiras atividades listadas representam as duas maiores médias dentre todas as atividades relacionadas nos demais blocos. Isso significa que os discentes possuem maior concordância em relação ao desenvolvimento de atividades como a 'semana do contador', que é um período com comemorações e palestras em homenagem ao dia do contador, sendo também bem aceita a proposta de realização de 'visitas técnicas em empresas para conhecer o funcionamento'. Nessa perspectiva, percebe-se que os discentes anseiam por uma maior interação acadêmica além das salas de aula. 
Por outro lado, a última atividade listada nessse bloco possui a menor média de todas as demais atividades listadas neste e nos outros blocos. Pode-se interpretar, então, que a atividade de 'oficina nas escolas/ interação com alunos do Ensino Médio/ programas desenvolvidos para crianças' é percebida pelos respondentes como a menos relevante para a formação dos alunos, não sendo necessário seu desenvolvimento.

Tabela 4 - Percepção dos alunos de Ciências Contábeis em relação às atividades de Extensão

\begin{tabular}{|l|c|c|}
\hline \multicolumn{1}{|c|}{ ATIVIDADES NA ÁREA DE EXTENSÃO } & Média & Desvio Padrão \\
\hline 1. Semana do Contador & 4,8340 & 4,5052 \\
\hline 2. Visitas técnicas em empresas para conhecer o funcionamento & 4,7315 & 0,6370 \\
\hline 3. Publicação de revista/ periódico com assuntos contábeis & 4,5403 & 0,7828 \\
\hline 4. Desenvolvimento de um Blog/ website da Contabilidade & 4,5168 & 0,8007 \\
\hline $\begin{array}{l}\text { 5. Organização de eventos que priorizam a responsabilidade social/ } \\
\text { projetos sociais/ trabalho voluntário }\end{array}$ & 4,2761 & 1,0157 \\
\hline $\begin{array}{l}\text { 6. Oferecimento de minicursos para transmissão de conhecimentos } \\
\text { básicos de contabilidade para a população }\end{array}$ & 4,2013 & 1,0049 \\
\hline $\begin{array}{l}\text { 7. Oficina nas escolas/ Interação com alunos do Ensino Médio/ } \\
\text { Programas desenvolvidos para crianças }\end{array}$ & 3,9765 & 1,1442 \\
\hline
\end{tabular}

Fonte: Dados da pesquisa.

A concordância dos alunos em desenvolver atividades na área de extensão é um importante fator para a evolução acadêmica. Isso se fundamenta no fato de que a extensão universitária é um dos princípios que constituem a base da universidade, sendo o primeiro passo na construção e adoção de políticas na área e na normalização das ações (FERREIRA, 2011, p. 104).

Conforme os resultados apresentados, pode-se observar que os discentes de Ciências Contábeis apoiam o desenvolvimento de atividades extracurriculares durante o curso, uma vez que concordam parcialmente ou totalmente com todas as atividades do PET elencadas no questionário. Esse resultado encontrado satisfaz a afirmação de Marion (2001 apud Castro, 2009, p. 11) de que "a educação para os futuros contadores deveria produzir profissionais que tivessem amplo conjunto de habilidades e conhecimentos".

O desenvolvimento dessas atividades no curso de Ciências Contábeis propiciaria aos graduandos a capacitação tanto para a mensuração de números e valores como para a cultura geral e humanística, o que é considerado essencial para a formação do contador, segundo Costa (p. 163, 2003 apud PELEIAS et al., p. 247, 2006). Dessa maneira, os alunos de grupos PET adquirem habilidades para se posicionar em um ambiente econômico, social e institucional, interagindo com pessoas e grupos distintos.

Então, estima-se que os graduandos de Ciências Contábeis possuem interesse em relação a uma maior interação acadêmica, sendo viável a inserção do PET nesse curso. Nesse contexto, destaca-se a necessidade de pesquisas futuras envolvendo os motivos pelos quais os cursos de Ciências Contábeis aparentemente possuem deficiências no tocante à realização de atividades extracurriculares, uma vez que os discentes consideram que tais atividades são relevantes para a formação acadêmica.

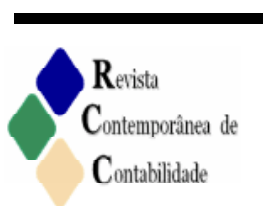




\section{Considerações Finais}

Este estudo buscou identificar a percepção dos alunos de Ciências Contábeis em relação às atividades desenvolvidas pelo PET de áreas afins. Nesse sentido, a pesquisa buscou oferecer contribuições por meio de propostas de atividades extracurriculares a serem realizadas pelo PET em Ciências Contábeis - ou outros projetos similares - com base na identificação das principais atividades realizadas por PET de áreas afins, com vistas à melhoria do curso e maior integração dos discentes com a vivência acadêmica.

Assim, realizou-se, primeiro, um estudo a respeito das atividades mais relevantes, de acordo com a percepção dos alunos petianos e tutores, desenvolvidas nos grupos PET dos cursos de Administração, Direito e Economia listados pelo MEC no ano de 2010. Nessa perspectiva, identificou-se que, no curso de Administração, a atividade considerada mais relevante foi a 'pesquisa coletiva focada em um tema definido pelo tutor', a qual se encontra inserida na área de pesquisa. No curso de Direito, a atividade mais relevante foi 'grupos de pesquisa/ pesquisa coletiva' na área de pesquisa. No curso de Economia, por sua vez, foram selecionadas as 'oficinas de debates/ discussão de textos' na área de ensino e 'participação em eventos científicos nacionais com apresentação de trabalhos/ publicações' na área de pesquisa como as atividades mais relevantes. Nesse sentido, pode-se interpretar que todas as atividades apontadas como relevantes pelos tutores e alunos dos grupos PET, em áreas afins do curso de Ciências Contábeis, podem ser testadas e desenvolvidas em grupos PET específicos para esse curso, devido à proximidade de conteúdo dos cursos e da flexibilidade das atividades.

Além da identificação das principais atividades realizadas pelos grupos PET analisados, foram apontadas as principais vantagens do desenvolvimento do PET para os alunos e cursos de graduação. Nessa perspectiva, de acordo com a percepção de tutores e alunos, foi identificado que o PET contribui, dentre outros fatores, para o 'crescimento profissional dos alunos petianos'. As vantagens proporcionadas pelo PET realçam as finalidades do ensino superior definidas por Andere e Araujo (2008, p. 93), conforme citado anteriormente: formação do cidadão, transmissão de cultura, disseminação do conhecimento, investigação científica, formação de pesquisadores, ensino de profissões e prestação de serviços à comunidade. No geral, ressalta-se a importância do Programa, bem como a necessidade de sua expansão e aprimoramento.

Quanto à percepção dos alunos de Ciências Contábeis da universidade mineira em relação às atividades caracterizadas na primeira parte da pesquisa, identificou-se que os discentes, em média, concordam (em parte ou totalmente) com o desenvolvimento no curso das atividades promovidas pelo PET nas áreas de ensino, pesquisa e extensão. Isso se torna perceptível devido ao fato de as médias se aproximarem dos números 4 e 5 , de acordo com a escala tipo Likert. Nessa perspectiva, as atividades mais relevantes apontadas por eles foram: 'seminários e palestras de profissionais', com relação ao ensino; 'eventos acadêmicocientíficos', na área de pesquisa; e 'semana do contador', em termos de extensão. Entretanto, todas as atividades submetidas à apreciação dos alunos receberam uma boa avaliação quanto à sua relevância, podendo estimar, assim, que os alunos deste curso aprovam a realização de um número maior de atividades extracurriculares, para o aprimoramento da interação acadêmica.

Em decorrência dos dados pesquisados, pode-se concluir que seria propício o desenvolvimento das atividades caracterizadas durante a pesquisa no curso de Ciências 
Contábeis, uma vez que proporcionaria aos graduandos maior interação com os docentes, capacidade de trabalhar em grupo e visão crítico-analítica. Dessa forma, também pode-se destacar a importância do desenvolvimento do PET para o cumprimento dos objetivos inerentes ao curso de graduação em Ciências Contábeis, estabelecidos pela CNE/CES n ${ }^{\circ}$ 10/2004, citados anteriormente durante a pesquisa.

Finalmente, recomenda-se a realização de pesquisas envolvendo as atividades desenvolvidas pelo PET em outras áreas do conhecimento, uma vez que os cursos de graduação pesquisados pertencem à área de Ciências Sociais Aplicadas. Nesse sentido, o estudo das ações promovidas pelo PET permite observar se as necessidades básicas expostas para os cursos de graduação estão sendo cumpridas, uma vez que o Programa abrange diretrizes previstas na Lei n. 9.394/1996 em relação aos objetivos fundamentais do ensino superior no Brasil, no momento em que incentiva o trabalho de pesquisa e investigação científica e promove a extensão aberta à participação da população.

\section{Referências}

ANDERE, Maira Assaf; ARAUJO, Adriana Maria Procópio de. Aspectos da formação do professor de ensino superior de Ciências Contábeis: uma análise dos programas de pós graduação.Revista Contabilidade \& Finanças - Universidade de São Paulo, São Paulo, vol. 19, n. 48, set./dez. 2008.

ANTUNES, Maria Thereza Pompa; MORAIS, José Fausto de; FORMIGONI, Henrique; LEITE, Rafael Soares. Tecnologias Educacionais em cursos de contabilidade avaliados no exame nacional de cursos (ENC)/ 2003 com conceitos A e B. UnB Contábil - Departamento de Ciências Contábeis e Atuariais da Universidade de Brasília, Brasília, vol. 8, n. 1, p. 61 a 80, jan./jun. 2005.

BERNARDO, Denise Carneiro dos Reis; NASCIMENTO, João Paulo de Brito; NAZARETH, Luiz Gustavo Camarano. Representações do Ensino, Pesquisa e Interdisciplinaridade dos Cursos de Ciências Contábeis no Estado de Minas Gerais. Contabilidade Vista \& Revista. Belo Horizonte, jul./set. 2010, v..21, n..3, p. 111-133.

BRASIL. Lei $\mathrm{n}^{\circ}$ 9.394, de 20 de dezembro de 1996. Estabelece as diretrizes e bases da educação nacional. Diário Oficial da República Federativa do Brasil. Brasília DF, 21 dez. 1996. Disponível em: <http://www.planalto.gov.br/ccivil_03/Leis/L9394.htm>. Acesso em 29 dez. 2010.

BRASIL. Conselho Nacional de Educação; Câmara de Educação Superior. Resolução CNE/CES 10, de 16 de dezembro de 2004. Institui as Diretrizes Curriculares Nacionais para o Curso de Graduação em Ciências Contábeis, bacharelado, e dá outras providências. Disponível em: <http://portal.mec.gov.br/cne/arquivos/pdf/rces06_04.pdf>. Acesso em 29 dez. 2010.

BREUNING, Felipe Freddo; MORAES, Ronaldo Dreissig de; CRUZ, Lucas Lopez da; MAZO, Janice Zarpellon. Memórias do Programa de Educação Tutorial da Educação Física da UFRGS (1991-2009). In: SALÃO DE INICIAÇÃO CIENTÍFICA - PUCRS, 10, 2009, Porto Alegre/RS. Anais... Porto Alegre/RS: X Salão de Iniciação Científica, 2009. Disponível em: <http://www.pucrs.br/edipucrs/XSalaoIC/index.htm>. Acesso em 25 mar. 2012. 
CASTRO, Adelvandro Felício de. Visão e Características do ensino da Contabilidade adotado no Brasil. Revista Mineira de Contabilidade. Belo Horizonte, $2^{\circ}$ trim. 2009, ano X, n. 34, p. 6 a13.

FERREIRA, Maria Mary. Produção Científica na Biblioteconomia: As Pesquisas Realizadas no Programa de Educação Tutorial (PET) e seus reflexos na formação acadêmica. Revista EDICIC, v.1, n.4, p.99-108, Oct./Dic. 2011. Disponível en: 〈http://www.edicic.org/revista/>. Acesso em 26 mar. 2012.

GIL, Antonio Carlos. Como elaborar projetos de pesquisa. 4. ed. São Paulo: Atlas, 2002.

LEAL, Douglas Tavares Borges; CORNACHIONE JR, Edgard. A aula expositiva no ensino da contabilidade. Contabilidade Vista \& Revista - Faculdade de Ciências Econômicas/ UFMG, Minas Gerais, vol. 17, n. 3, p. 91 a 113, jul./set., 2006.

LEAL, Edvalda Araújo; OLIVEIRA, Cíntia Rodrigues Medeiros de; MIRANDA, Gilberto José. Interdisciplinaridade no Curso de Ciências Contábeis: Os desafios e as possibilidades de aprender e ensinar a partir de uma experiência. In: IV CONGRESSO ANPCONT, 2010, Natal/RN. Anais... Natal/RN: 1 CD-ROM.

MARTINS, Iguatemy Lucena. Educação Tutorial no ensino presencial: uma análise sobre o PET. Brasília: Ministério da Educação. 2007a.

MARTINS, Lígia Márcia. Ensino-pesquisa-extensão como fundamento metodológico da construção do conhecimento na universidade. Oficina de Estudos Pedagógicos, São Paulo, 2007b. Disponível em: 〈http://www.franca.unesp.br/oep/>. Acesso em 4 jan. 2011.

MEC- MINISTÉRIO DA EDUCAÇÃO - MEC. Programa de Educação Tutorial. Apresentação PET. 2010a. Disponível em: <http://portal.mec.gov.br/index.php> Acesso em 4 dez. 2010.

MEC - MINISTÉRIO DA EDUCAÇÃO. Programa de Educação Tutorial. Grupos PET 2010. 2010b. Disponível em: <http://portal.mec.gov.br/index.php> Acesso em 23 dez. 2010.

MEC - MINISTÉRIO DA EDUCAÇÃO. Programa de Educação Tutorial. Manual de Orientações Básicas do Programa de Educação Tutorial. Brasília: 2006. Disponível em: <http://portal.mec.gov.br/index.php> Acesso em 8 dez.. 2010.

NOGUEIRA, Daniel Ramos; ESPEJO, Márcia Maria dos Santos Bortolocci. O impacto do estilo de aprendizagem no desempenho acadêmico: um estudo empírico com alunos das disciplinas de contabilidade geral e gerencial na educação à distância. In: IV CONGRESSO ANPCONT, 2010, Natal/RN. Anais... Natal/RN: 1 CD-ROM.

PELEIAS, Ivam Ricardo (coord.). Didática do Ensino de Contabilidade: Aplicável a outros cursos superiores. São Paulo: Saraiva, 2006. 348 p.

SILVA, Soraya Petla; QUIMELLI, Gisele A. de Sá. A extensão universitária como espaço de formação profissional do assistente social e a efetivação dos princípios do projeto éticopolítico. Revista Emancipação - UEPG. Paraná, vol. 6, n. 1, p. 279 a 296, 2006.

SONTAG, Anderson Giovane; HUFF, Giovane; HOFER, Elza; LANGARO, Jerri Antonio. Fatores que influenciam a opção pelo curso de Ciências Contábeis. In: VI SEMINÁRIO DO 
CENTRO DE CIÊNCIAS SOCIAIS APLICADAS DE CASCAVEL, VI, 2007, Paraná. Anais... Paraná, 2007. Disponível em: <http://www.unioeste.br/campi/cascavel/ccsa/VI\%20

Seminario/>. Acesso em 4 jan. 2011.

VIEIRA, Maria das Graças. As competências e as habilidades requeridas aos professores de contabilidade. Revista Brasileira de Contabilidade - Conselho Federal de Contabilidade, ano XXXVII, nº169, jan./fev. 2008.

XAVIER, Bruno Toribio de L.; GOULART, Daniel Franco. Ensino, pesquisa e extensão consorciados: a fórmula do sucesso do Programa de Educação Tutorial/PET. PETCOM, Bahia, 2007. Disponível em: <http://www.petcom.ufba.br/documentos/documentos.htm>. Acesso em 3 jan. 2011. 